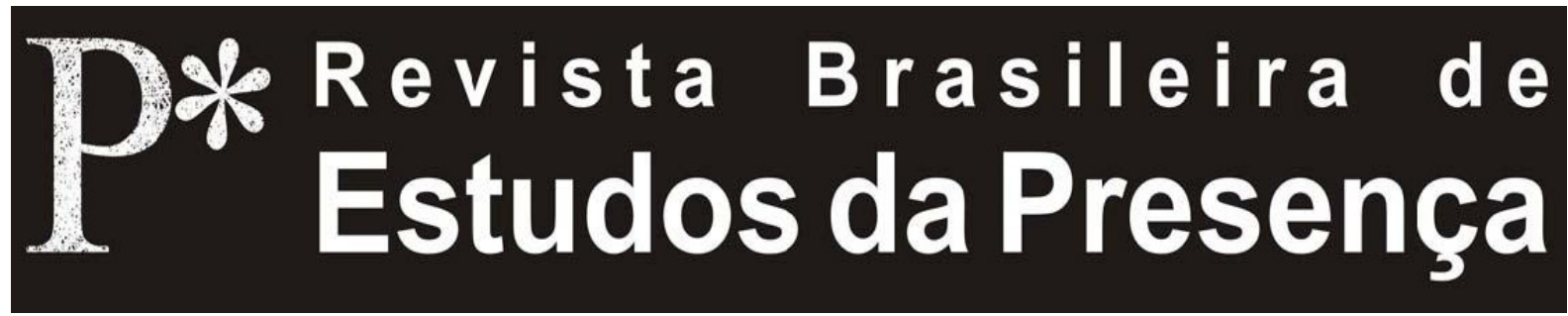

DOI - http://dx.doi.org/10.1590/2237-266025638

ISSN 2237-2660

\title{
El Giro Conceptual del Teatro: a propósito de la investigación escénica
}

\author{
Luis Fernando Loaiza Zuluaga \\ Universidad de Caldas - UdeC, Manizales, Colombia
}

RESUMEN - EI Giro Conceptual del Teatro: a propósito de la investigación escénica - En el presente escrito se intenta comparar la función cumplida por el concepto en la producción teatral clásica y contemporánea. Se sostiene que después de cumplir una misión representacional, el concepto se ha desplazado hacia la producción teórica que sostiene previa o posteriormente la producción escénica contemporánea. Finalmente, al aceptar que el lenguaje y el concepto son también una dimensión humana, se propone una visión de la producción teórica universitaria como acontecimiento y como experiencia estética.

Palabras-clave: Concepto. Teatro. Investigación. Explicitación. Acontecimiento.

ABSTRACT - Theatre's Conceptual Turn: on theatre performance investigation - The present paper attempts to compare the role of concept in classical and contemporary theatre. It is argued that after performing a representational function, concept has shifted to the theoretical output that underpins contemporary stage productions, previously and subsequently. Finally, by accepting that both language and concept are human dimensions too, we propose a point of view in which academic theoretical production is regarded as event and aesthetic experience. Keywords: Concept. Theatre. Academic Research. Explication. Event.

RÉSUMÉ - La Tournant Conceptuel du Théâtre: la recherche scénique - Le présent article s'efforce de comparer le rôle joué par le concept dans la production théâtrale classique et contemporaine. Il soutient qu'après avoir accompli une mission de représentation, le concept se déplace vers une production théorique qui intervient avant ou après la mise en scène contemporaine. Finalement, en acceptant que la langue et le concept possèdent également une dimension humaine, il est possible d'envisager la production théorique universitaire en tant qu'événement et expérience esthétique.

Mots-clés: Concept. Théâtre. Recherche. Explicitation. Événement. 
Actualmente el teatro se encuentra configurando nuevas sendas para recorrer y comprenderse a sí mismo, tanto en la práctica como en la teoría. Parece que subsisten y se interrelacionan dos grandes marcos de comprensión: por una parte, el teatro dramático, ligado a los procesos representacionales. Por otra, un conjunto de formas expresivas de diversa índole ligadas, sobre todo, a la auto referencialidad y la naturaleza que le es propia al teatro. Actualmente se destacan indagaciones que ponen de relieve la presencia del actor y la liberación de los sentidos, proceso que lleva poco más de un siglo.

En este camino, durante buena parte del siglo XX, el teatro se encontró ante el monstruo de la idea de progreso heredada de la modernidad y sus colaterales efectos de dominación. Por una parte inician indagaciones de lucha a través de la contra-información. Tal es el caso de Brecht (1973) o de Piscator (1973) quienes abogan por un teatro de denuncia de los sistemas de poder el cual promueva la agitación intelectual que apunte a la comprensión de las estructuras dominantes. Otras indagaciones sugieren la reelaboración del arte como dispositivo de resistencia (Deleuze, 2003) y su autopromoción como posible salida del mundo ilusorio: generando ahuecamientos en la realidad, el ente poético resurge para dar nuevas pistas frente al misterio de la vida a través de la auto-referencialidad; tal es el caso de propuestas como las de Deleuze (2000), Craig (1957), Appia (1997), Artaud (1996), Grotowski (1970), quienes, cada uno a su manera, intentan profundizar el teatro y su propia naturaleza, evitando materiales exógenos, de forma que se generen otros movimientos y la liberación de nuevas fuerzas.

A medida que avanzan las indagaciones, el acontecimiento teatral sigue sustentándose en lo que le queda de identidad: el encuentro entre ejecutante y expectante. Y de esta relación se generan múltiples variantes de creación que apelan a la sensorialidad, a la provocación de los sentidos. El teatro encuentra la posibilidad de volver sus ojos hacia el acontecimiento: ya no a la fábula, sino al acontecimiento presente; al acontecimiento verdadero. Una nueva vuelta de tuerca: otrora cumplía la misión de representar la vida; hoy, ante la ficción 
de la vida, intenta reencontrarla, presentarla, desnudarla. Y es en esta desnudez que el ser humano se sorprende al ver que el escenario le muestra lo que la vida misma ya no puede. Es como si el escenario y la vida hubieran cambiado de lugar.

El teatro evita caer en las trampas del mundo falsificado y espectacular (Chevallier, 2004). Apela las más de las veces a la provocación de los sentidos. Tanto a los sistemas sensoriales como a la producción de sentido libre por parte del espectador. Al promover acontecimientos vitales, se apela a la vivencia presente; aquí y ahora. Lo que se ve, lo que se oye, lo que se huele, lo que se degusta o lo que se palpa en el escenario no representa otra cosa que lo que hay allí. No se intenta contar una historia o enviar un mensaje. Se pretende vivificar las experiencias humanas en acontecimientos rituales o cuasirituales sin andamiajes religiosos.

Con estas nuevas visiones nos acercamos a un nuevo teatro, que nos empuja con mayor fuerza hacia la incertidumbre vital... o quizá lo que hacemos al desprendernos del concepto representado, del drama, de la fábula y del mensaje, no es otra cosa que regresar y negar veintiséis siglos de historia teatral. Quizá lo que hacemos es volver al ritual del cual surgió el teatro, orientado hacia celebraciones hedonistas, pues el futuro pareciera no ofrecer nada: Quizá nos encontramos frente a un eterno retorno del teatro dirigido hacia el futuro para volver a su pasado. Una tensión entre la búsqueda del teatro del futuro y el retorno a los orígenes.

\section{El Concepto en el Teatro Dramático}

Ubiquémonos por un momento en el primer marco de comprensión. El teatro dramático, dispersado con múltiples rostros en el camino de este posible retorno: Desde el teatro griego clásico hasta los albores de la edad contemporánea se sustentó en la mímesis como estructura fundamental generadora del placer estético y de la función del teatro. Esta mímesis ubicó al autor como eje dominante durante casi veintiséis siglos. Éste se encargaba, en principio, de reestructurar los mitos en nuevas cadenas de acontecimientos que brillaran por su coherencia interna y por su capacidad de identificar y 
movilizar al espectador. El autor, además de encontrar en el mito su fuente de inspiración, se enfocaba en la realidad como punto de referencia para resistir las dudas del sentido común de lectores y espectadores.

Su mayor arma, por tanto, sería la dialéctica entre lo real y lo imaginario (Abirached, 1994). Incluso en las fábulas más originales, las fuentes de inspiración serían, cuando menos, estructuras arquetípicas. Estas estructuras establecerían múltiples variantes del conflicto entre sujeto y colectividad, las cuales serían respuesta a las condiciones propias de la cultura o quizá una crítica a ésta.

El espectador debería comprender de la forma más eficaz posible el conjunto de relaciones establecidas entre acciones, personajes, circunstancias y conflictos, y tener la capacidad de elaborar sus percepciones sobre la realidad objetiva. No obstante, esta visión del espectador sobre la realidad objetiva estaría mediada por la visión del autor. Así, pues, el papel del creador teatral (director, actor, etc.) sería compartir con el espectador su propia visión del mundo a través del argumento diseñado por el autor.

Por su parte, para que el espectador pudiera establecer también su función, tendría que decodificar el conjunto de elementos sugeridos en el escenario y aceptados por él como verdaderos en el universo de ficción (Loaiza Zuluaga, 2012). Aunque hubiera un alto contenido emocional en el proceso de identificación, este proceso estaría mediado por el concepto, pues el espectador sólo poseería la capacidad de emocionarse o identificarse con aquello que pudiera comprender. Es decir, pues, que además de aceptar en su mente un universo de ficción, tendría que tomar partido en el marco de las problemáticas planteadas en la obra teatral, lo cual no es otra cosa que traducir el conjunto de elementos escénicos por un conjunto de contenidos mentales que le permitieran juzgar lo escenificado a través de conceptos. En otras palabras, a pesar de permitir a la obra comunicarse a través de los sentidos, el espectador tendría que etiquetar todos sus elementos, tanto los estructurales como los formales. Así, pues, la medida de la obra estaría dada por un juicio estético establecido por el 
espectador. De tal forma, que aquellas obras con mayor efectividad comunicativa (incluso en el plano de lo ambiguo) serían aquellas que pudieran ser decodificadas con mayor precisión y que lograrían que el espectador tomara partido. Las obras tendrían que estar minuciosamente codificadas a nivel estructural y formal, logrando que todo elemento cobrara sentido en la escena, fuera en el plano dialógico o en el plano plástico u operativo. La clave estaría dada por el nivel de coherencia y potencia de la fábula, es decir, el conjunto de acontecimientos narrativos.

Por ello, el camino establecido sería el siguiente: La fábula contendría un conjunto de acontecimientos que el autor condensaría en un argumento, el cual a su vez contiene un nuevo conjunto de acontecimientos transferidos al diálogo. Para ponerlo en escena, este diálogo se traduciría en un conjunto de códigos escénicos y estos a su vez serían decodificados por el espectador, quien a través del proceso dialéctico intelecto-emoción, tendría la capacidad de tomar partido y revisar su realidad objetiva. ¿No tiene, pues, el concepto un valor central en esta red comunicativa? Aunque supusiéramos un alto contenido semiótico extralingüístico, éste estaría diseñado para lograr una alta eficacia comunicativa, la cual no es posible lograr más que a través de una poderosa relación entre significante y significado, es decir, un código altamente convencionalizado. Por esta razón, la hipótesis, es que el teatro dramático ataca la emoción a través de su relación con el intelecto, pues sólo tomamos partido por aquello que podemos entender. El concepto es, por lo tanto, pieza clave en el fenómeno comunicativo establecido en el teatro dramático.

\section{EI Concepto y la Ilusión del Mundo}

Volvamos al segundo marco de comprensión: A partir de los inicios de los procedimientos llamados vanguardistas llevados a cabos en la edad contemporánea, hay una mayor ruptura de los códigos estéticos. Tanto más cuanto que los creadores teatrales inician una misión de derrocamiento de los elementos de poder, del logocentrismo, de la mímesis, del personaje, de la fábula y de la comunicación. Así, se encargan poco a poco 
de asignarle mayor relevancia a la autonomía del teatro. De esta autonomía surgen manifestaciones heterogéneas que se alejan del papel asignado al teatro de contar historias y éste busca nuevas formas de proceder y de encontrar su identidad.

Este proceso se debe en gran parte al cada vez mayor conjunto de creencias destruidas de la sociedad occidental. Tanto el avance de las ciencias como la liberación del individuo acentúan la duda frente a la realidad. La realidad se ve dispuesta de forma artificial; se puede dudar ante todo, incluso ante las creencias más arraigadas de la sociedad. Los roles, las instituciones y las estructuras se derrumban a la vez que todo se manifiesta engañoso, manipulado, alienado. El ser humano, en su afán de progreso, se ha encontrado en un abismo lleno de incertidumbre que no garantiza un futuro verdadero. El ser humano ya no sabe en qué creer; es más, ya no sabe si es necesario creer.

La representación ilusoria del mundo se hace cada vez más evidente y el concepto pierde poder. Los seres humanos confían cada vez más en su intuición y cada vez menos en las normas. Lo que se aceptaba como tradición, se observa con sospecha; se exacerba una visión hedonista de la vida, de valoración del placer sensual y estético. No obstante, la ilusión reaparece con otra máscara y se reubica en los medios de comunicación masiva que aparecen tan potentes y multiplicados como les es posible. Estos medios emergen exacerbando la representación del mundo y desvirtuando la producción artística. Ahora el arte cumple misiones obsoletas, exceptuando los grandes espectáculos de masas que se encargan de promover los sistemas de poder. A través de la masificación de la información se logra por décadas sostener un nuevo imperio que apenas si es rasguñado por la producción artística.

El concepto, en consecuencia, se encuentra manipulado. No tenemos el alcance para detener los significados intencionales dispuestos por las estructuras de poder. No obstante, en el acto de resistencia, hay que aceptar que el concepto se constituye en una herramienta efectiva de construcción del mundo y no sólo de su nivel de explicitación, por cuanto nos ayuda a construir una imagen de mundo, pues es imposible 
escapar a la representación (Enaudeau, 1998): aunque intentemos absorber el mundo, nuestros sentidos están dispuestos para ayudar a la mente a construir una imagen del mismo. Los sentidos en sí mismos son legítimos; no obstante, el ser humano produce una imagen mental de lo sentido, produce conceptos que dibujan una imagen del mundo, un reflejo. Aunque el concepto nos engaña, pues nos muestra ilusiones y sombras, es él quien nos permite identificar la insuficiencia de la ilusión. Es decir, el concepto juega para los dos bandos: por una parte nos representa y espectaculariza el mundo; por otra nos ayuda a hacernos conscientes de tal falsificación. Sin el concepto, sin un lenguaje que lo explicite para el individuo o para el colectivo, sería imposible desenmascarar al mundo nuevamente.

\section{A Propósito de la Investigación Escénica}

Hoy en día los medios masivos han llevado la información a tal nivel que ellos mismos se han saturado. Ni los medios oficiales, ni los medios extraoficiales, ni las contrainformaciones independientes escapan a la duda. Hay tal nivel de redundancia y tantas versiones de la realidad que la imagen del mundo se ha hipertrofriado y el ser humano sólo juega con los conceptos para tratar de entenderlo. Aun así, todos los caminos comunicativos llegan finalmente a la incertidumbre.

Ahora bien, en el teatro, aunque el concepto ya no se codifique y decodifique a través de mitos, fábulas y personajes, ha encontrado un nuevo lugar. Por una parte, al llegar el arte a la producción de acontecimientos sin aparente intención comunicativa, surgen sinnúmero de preguntas que atacan y contraatacan la producción escénica, a las cuales sólo se logra responder con la explicitación teórica. En otras palabras, el concepto ha salido del contenido escénico para volverse su lupa, su marco de referencia. La producción escénica se sustenta en un compendio de manifiestos o de explicitaciones teóricas que intentan hacer comprensible lo que el acontecimiento ya no quiere o no puede. Se generan, en consecuencia, dos ramas de producción: la práctica escénica y la explicitación teórica. En este proceso, el concepto implica una comprensión de la 
teatralidad que supone una búsqueda de las posibilidades del teatro, un registro de lo desarrollado y la apertura al conocimiento sobre el teatro. No obstante, cabe preguntarse si el teatro realmente necesita un nivel de explicitación, pues asumir esta posición implicaría deslegitimar la producción escénica en sí, para promover la palabra que la reemplaza.

Esta explicitación teórica moviliza un nuevo desplazamiento: ante la destrucción de las instituciones (entre ellas la institución arte) y la hibridación actual, la producción escénica se desplaza a otras instituciones: La cultural y la académica. En la primera, la práctica escénica debe ser justificada en el marco de un sistema de creencias $\mathrm{y}$, además, explicada en formatos; ya no se produce arte con efectos en la cultura, sino que la institución cultural exige argumentos previos para socializar un producto creativo. En la segunda, los académicos insistimos en tratar de poner en palabras lo que nuestros sentidos nos ofrecen; intentamos conocer e interpretar la escena. La producción escénica se hibrida con dos monstruos llenos de formatos y procedimientos. En la institución cultural se requiere, para recibir apoyo para crear, explicitar previamente los alcances de la creación y, además garantizar fechas, características y efectos del producto final u obra de arte. En la institución académica y especialmente en nivel superior, se reubica la creación en proximidad con la función sustantiva de la investigación; posteriormente se produce un fenómeno novedoso: la investigación en artes... múltiples miradas para enfocar relaciones entre la producción de conocimiento y la producción de experiencias estéticas.

Las universidades, influenciadas por un marco científico, anclan la producción escénica a diversas unidades académicas. No es muy claro aún si una obra (en sí misma) sirve para generar conocimiento, para aportar a la sociedad, para generar ingresos a las universidades [...] O, ¿para qué ha servido la etapa de integración de los artistas al mundo académico? ${ }^{1}$ Ahora bien, bajo esa ambigüedad del arte en la academia, hemos terminado por aceptar una lucha entre la creación y la investigación dado que detrás de la supuesta inclusión de los procesos creativos en la convocatorias de investigación se 
esconde una imposición de la idea de investigación por encima de la de creación; una idea del científico por encima del artista. Entiéndase que no se sugiere que no haya investigación en artes; y además, hay que aceptar que la creación tiene un poco de investigación y la investigación un poco de creación (Pérez Rasilla, 2010). La cuestión es que sería preocupante ver que los artistas tuviéramos que estar midiéndonos en comparación con la ciencia en términos de creación.

La investigación escénica universitaria sugiere varias trampas: publicar por ganar puntos, investigar para aumentar salarios, investigar para disminuir la labor académica, por tener reconocimientos y una larga de lista de beneficios. Se viene promoviendo aceleradamente el apoyo a procesos de investigación escénica que en ocasiones asumimos acríticamente. En ocasiones parece que se impusiera mucho más como una moda, como una forma de obtener recursos para la creación, o, en el peor de los casos, un esfuerzo por ponernos al nivel de los científicos. De aquí se desprenden al menos tres cuestiones importantes ${ }^{2}$ :

a) ¿Para qué llamar investigación a lo que ya se denominaba creación?

En este sentido de la discusión se encuentra la aplicación de convocatorias de investigación para crear obras escénicas. ¿Por qué cambiarle el nombre a lo que ya tiene? ¿Por qué hablar de investigación cuando estamos hablando de creación? ¿Qué ganamos con cambiar de nombres? ¿Acaso la creación escénica está por debajo de la investigación? Pareciera que la cuestión radicara, en aras de recibir reconocimiento y apoyo económico, en hacerle el juego a la estructura burocrática y dejar que intenten manipularnos mientras nosotros aprovechamos y encontramos formas de soportar nuestro quehacer. b) ¿Investigación aplicada: los productos de la creación son las obras de arte?

Si no se trata única y exclusivamente de generación de teorías, sino de productos que coadyuven a mejorar la relación del ser humano con el mundo o con su quehacer, no basta con decir que la investigación aplicada en arte genera obras de arte, pues, ¿no era originalmente lo que se hacía en el arte? ¿A qué 
productos, entonces, podríamos referirnos? Supongamos que el aporte de la investigación aplicada permitiría la generación de dispositivos utilizables en el quehacer escénico. Digamos entonces que ayudaría a economizar en la producción artística. En el peor de los casos se trataría de posibilitar mayor eficacia en los procedimientos de creación artística.

c) ¿Qué aporta a la vida teorizar sobre el arte?

Si se trata de investigar, cabe plantear que lo que se produzca sea generación de conocimiento original sobre algún fenómeno relacionado con el arte: procesos, sujetos, circunstancias y productos. Y esto también orienta múltiples posibilidades: en principio, la posibilidad de que la producción investigativa se genere desde el interior de un proceso de creación o que sea generada desde el exterior. Es decir, en caso de que realmente la investigación aporte generación de conocimiento en torno a cualquiera de los fenómenos relacionados con el arte, se puede hacer por parte de los propios artistas, en medio de un proceso creativo, procurando dar cuenta de inquietudes teóricas en torno a un problema específico; o se puede hacer por parte de investigadores externos, quienes se encargan de sistematizar lo que los artistas producen ${ }^{3}$. En ninguno de los casos enunciados puede la teoría emergente garantizar la producción de obras de arte más completas. ¿De qué va entonces la investigación en arte? O puesto en otras palabras: ¿a quién le interesa que se investigue sobre el arte? Supongamos por ahora que el valioso aporte de la teoría artística es lo que nos permite comprender con mayor precisión y profundidad el entramado que se establece en los fenómenos artísticos y que estos, a su vez, nos ayudan a darle sentido al arte y a la propia vida. Nos centraremos exclusivamente en esta última cuestión.

\section{El Nuevo Lugar del Concepto o la Explicitación Teórica como Experiencia Estética}

Podríamos, ante estos cuestionamientos, sugerir que la explicitación teórica también pone formas de ver el mundo en evidencia. Sólo para plantear un ejemplo, podemos considerar el trabajo de Antonin Artaud: Incansable director escénico, fue un visionario del teatro; supuso una visión revolucionaria 
del teatro, un teatro vivo, lleno de elementos sensoriales, planteando nuevas relaciones entre actor y espectador, abogando por un poder inexplicable de la escena teatral. No obstante, en la práctica, le fue imposible cumplir con las explicitaciones que había formulado en el papel. En otras palabras, sólo pudo cumplir con su meta a través de la retórica. Su libro más conocido, El teatro y su doble (1996), un compendio de múltiples reflexiones hechas a lo largo de su vida, tiene infinidad de seguidores que admiramos su visión de un teatro pestilente, que destroza la vida, que derrumba los muros impuestos por la cultura. Y tenemos otros ejemplos como el de Grotowski (1970), quien contara con mayor cantidad de defensores prácticos y haría una mayor defensa del trabajo sobre la práctica; o de Brecht (1973) quien construye toda una visión del teatro oponiéndose directamente a la estética Aristotélica. En los tres ejemplares casos (aunque habrán muchos más) el concepto, aunque atacado, expuesto y abierto, al ser puesto en el papel se constituye en un umbral de comprensión de sus visiones sobre el teatro. Pero aquí habría que plantear otra cuestión: ante la lectura de su visión de teatro (es decir, no de sus obras de teatro sino de su construcción teórica) nos regocijamos estéticamente. Es como si su obra teórica se hubiera convertido a sí misma en obra de arte, o mejor, en visión poética. $\mathrm{Y}$ es en este sentido que podríamos re-evaluar el papel de la investigación escénica y además de la producción teórica que de allí se desprende.

Podemos defender la producción escénica sin pretender plantear de forma explícita la intención. Es decir, es legítimo aceptar la producción escénica sin constructos teóricos que le den sustento y aceptarlas tal cual son, como evento. El teatro no es más que el encuentro entre actor y espectador; no necesita nada más. No obstante, aquí la duda radicaría en el papel que cumpliría una producción escénica sin intención ni justificación, sin nivel de explicitación; en otras palabras una práctica escénica de tales cualidades pone en duda la necesidad de una función, pero desde la producción artística prehistórica, la colectividad ha asignado una función más o menos espontánea al arte (Hauser, 1963). Algo nos moviliza a producir arte; 
y aunque bien vale la pena dejar que la experiencia creativa nos desborde en el delirio, hay un misterio constante que nos avasalla y nos moviliza en la búsqueda de respuestas. Es en este sentido que otra posibilidad podría plantearse, nuevamente, al ver las cuestiones al contrario: ¿Y si mejor aceptamos que la construcción teórica es en sí misma una acción? ¿Podríamos pensar en la producción teórica como producción poética? Poética en el sentido más amplio de la palabra; es decir, creativa, inventiva, fecunda. Al traducir una práctica escénica a través de la sistematización o de la investigación, o al prefigurar una teoría a la misma producción y confrontarla con la comunidad escénica y/o académica, estamos, pues, haciendo parte de un accionar. Apelando a los actos de habla (Austin, 1955; Searle, 1994): por una parte representamos el estado de las cosas a través de la teoría y, por otra, nos comprometemos con dicha teoría. De esta forma, también afectamos el mundo. Poner en juego la teoría que se desprende (previa o posteriormente) de la práctica escénica es también una forma de afectar la realidad, pues el lenguaje es esencialmente un fenómeno ligado a la existencia humana; esconder el lenguaje sería provocar lo mismo a lo que nos resistimos: No enmascaramos las dimensiones humanas, pero ocultamos una de ellas (el lenguaje).

Observemos que la teoría que se desprende de la producción poética está profundamente permeada por la esencia del arte. Sistemática o no, la explicitación teórica de la idea de teatro o de escena incluye una intención estética e ideológica. La lectura, la escucha o la comprensión de dicha explicitación producen una sensación de experiencia vital también en aquel que la recibe. En otras palabras, hay seducción; se produce una experiencia estética. El contenido mental esta vez no apela a la comprensión de un mensaje o de un referente, sino del teatro mismo, o tal vez al concepto de teatro; y esta comprensión produce placer estético, por cuanto devela o sugiere la revelación de los secretos del arte escénico. Y como ya se ha dicho, al revelar el teatro se revela el misterio de la vida misma. Vista de esta forma, la investigación escénica no se asume como una normativa que exige explicaciones de anaquel que se convierten en palabras muertas. Se constituye mejor en un 
reto para la producción poética; un nuevo lugar del concepto como detonante de la acción y de la experiencia estética. La teoría, después de haber cumplido una función institucional, cumple un lugar central en la producción escénica contemporánea, pues brinda la oportunidad de desnudar nuestra visión de teatro de la forma más honesta posible ante la imposibilidad de renuncia a una las herramientas más complejas del ser humano: el concepto. 


\section{Notas}

${ }^{1}$ Aunque en un principio los académicos se encargaran de estudiar los fenómenos relacionados con el arte, nos encontramos ahora con artistas inmersos en la institución académica y promoviendo nuevos estudios desde adentro. Se trata de una hibridación que sugiere la construcción de conocimiento en torno al teatro. Las agrupaciones teatrales, a su vez, están produciendo teoría a partir de sus propias experiencias y de diversos eventos en torno al quehacer escénico.

${ }^{2}$ Permítasenos por ahora abordar las dos primeras de forma superficial, pues en este artículo nos interesa desarrollar sólo la tercera. La idea principal es que la investigación en arte, a su vez, empieza a encontrar nuevas dimensiones que le son propias. No obstante, discurrir sobre las dos primeras cuestiones implicaría ampliar demasiado la discusión.

${ }^{3}$ Es más, no es condición necesaria que se investigue en el marco de un determinado proceso creativo; es importante resaltar que los fenómenos en torno al arte escénico no se agotan en el producto y, de esta forma, la investigación en artes sigue constituyendo un panorama fértil de indagación. 


\section{Referencias}

ABIRACHED, Robert. La Crisis del Personaje en el Teatro Moderno. Madrid: Asociación de Directores de Escena de España, 1994.

APPIA, Adolphe. The Work of Living Art and Man is the Measure of All Things. Ed. Bamard Hewitty. Traducción de Coral Gables. Florida: University of Miami Press, 1997.

ARISTOTELES. Poética: introducción. Traducción de Griego y notas Angel Capelletti. Venezuela: Monte Avila, 1990.

ARTAUD, Antonin. EI Teatro y su Doble. Traducción de Enrique Alonso y Francisco Abelenda [Paco Porrúa]. Barcelona: Edhasa, 1996.

AUSTIN, Jhon. Cómo Hacer Cosas con Palabras. Santiago: ARCIS, 1955.

BRECHT, Bertolt. Pequeño Organón para el Teatro. Buenos Aires: Nueva Visión, 1973.

CHEVALLIER, Jean-Frédéric. Introducción: hacia un teatro del presentar. En: COLOQUIO INTERNACIONAL SOBRE EL GESTO TEATRAL CONTEMPORÁNEO, 1., 2004, México. Actas... México: Escenología/UNAM/UCM/Proyecto3, 2004.

CRAIG, Edward Gordon. Del Arte del Teatro. París: Hachette, 1957.

DELEUZE, Gilles. ¿Qué es el Acto de Creación? En: Deux régimes de fous. Textes et entretiens 1975-1995. Traducción de Hernan Ulm. Paris: Les Editions de Minuit, 2003.

DELEUZE, Gilles. Diferencia y Repetición. Buenos Aires: Amorrortu, 2000.

ENAUDEAU, Corinne. La Paradoja de la Representación. Santiago: ARCIS, 1998.

GROTOWSKI, Jerzy. Hacia un Teatro Pobre. México: Siglo XXI Editores, 1970.

HAUSER, Arnold. Historia Social de la Literatura y el Arte. Madrid: Guadarrama, 1963.

LOAIZA ZULUAGA, Luis Fernando. Conocimiento y Creación: la creencia y la justificación en el hecho teatral. Cátedra de Artes, Santiago, v. 9, p. 77-86, Universidad de Chile, 2012.

PÉREZ RASILLA, Eduardo. La Creación Escénica como Forma de Investigación y la Investigación como Forma de Creación: la representación y la disociación como procedimientos de investigación en las artes escénicas. Revista Telón de Fondo, Ciudad Autónoma de Buenos Aires, n. 12, dez. 2010. Disponible en: <http://www.telondefondo.org/numeros-anteriores/ numero12/articulo/311/la-creacion-escenica-como-forma-de-investigacion-y-la-investigacioncomo-forma-de-creacion-la-representacion-y-la-disociacion-como-procedimientos-de-investigacion-en-las-artes-escenicas-.html>. Consultado en: 17 nov. 2011.

PISCATOR, Erwin. Teatro Político. Cuba: Instituto Cubano del Libro, 1973.

SEARLE, Jhon. Actos de Habla: ensayo de filosofía del lenguaje. Traducción de Luis Valdés Villanueva. Madrid: Editorial Cátedra, 1994. 
Luis Fernando Loaiza Zuluaga es docente de la Universidad de Caldas, adscrito al departamento de Artes Escénicas, en la ciudad de Manizales, Colombia. Magister en Educación. Licenciado en Artes escénicas con énfasis en Teatro. Investigador, Director, Actor y Docente Teatral.

E-mail: luis.loaiza@ucaldas.edu.co

Recebido em janeiro de 2012 Aprovado em maio de 2012 